\title{
Interpersonal Communication Competence in SME Internationalization
}

\author{
PIPSA PURHONEN, University of Jyväskylä, Finland
}

\begin{abstract}
Facing economic globalization, internationalization has become the lifeblood for many small and medium sized enterprises (SMEs). The aim of this paper is to illustrate internationalization of an SME as a challenge to interpersonal communication competence. In international business, the competition for products, prices and technologies has expanded to successful development and management of business collaboration and international networks. Networks are created, developed and maintained through social interaction. Therefore it is a necessity to analyze what is interpersonal communication competence in the formation, development and maintenance of such interpersonal relations that are successful for SMEs in their efforts of internationalization.
\end{abstract}

Building upon existing literature on interpersonal and intercultural communication, communication networks and SME internationalization, this theoretical paper aims to examine demands of internationalization from the perspective of interpersonal communication competence of SMEs' owner-managers and employees.

The present paper is based on the author's doctoral dissertation under preparation and supervised by Professor Tarja Valkonen, Department of Communication, University of Jyväskylä

\section{KEYWORDS}

interpersonal communication, intercultural communication, competence, SME internationalization, networks.

\section{Introduction}

Interpersonal relations can be an asset or a stumbling block in international business. In this paper internationalization of small and medium sized enterprises (SMEs) is viewed as a challenge to interpersonal communication competence. The central goal of this paper is to examine what is interpersonal communication competence in the context of SME internationalization.

The conceptualization of interpersonal communication competence in SME internationalization is approached from three different perspectives: interpersonal communication competence, intercultural communication competence and network competence. These three perspectives are derived from the context of SME internationalization. Internationalization literally means geographical expansion of activities over a nation's borders (see Ruzzier et al, 2006). In addition to financial 
efforts, SME internationalization requires efforts in cooperation and networking both locally and globally (see e.g. Lindell \& Karagozoglu, 1997; Sternberg, 2000). Often faced challenges in SME internationalization are limited personnel and financial resources, as well as insufficient expertise and skills (Forsman et al, 2002). Networks can provide access to the lacking information and know-how and create new relations needed in internationalization.

Networking, again, is realized with interpersonal communication. Networks are created, developed and maintained through social interaction and interpersonal relations. Finally, along with internationalization, contexts of communication and interaction become increasingly intercultural. Therefore, when conceptualizing interpersonal communication competence in SME internationalization, it is reasoned to take account of the perspectives of interpersonal communication competence, intercultural communication competence and network competence.

These three perspectives descend from different disciplines. While the concepts of interpersonal communication competence and intercultural communication competence have been explicated especially in fields of communication studies and psychology, network competence as a concept has its roots in business studies.

In this paper the concept of interpersonal communication competence is first introduced. Second, conceptualization of intercultural communication competence is brought up. And third, findings of network competence are discussed. As a conclusion, synthesis of these three perspectives is made aiming to define what kind of interpersonal communication competence is needed in the formation, development and maintenance of such interpersonal relations that are successful for SMEs in their efforts of internationalization.

\section{Interpersonal communication competence}

The road of conceptualizing interpersonal communication competence can be long and complex as interpersonal communication competence has been illustrated and defined in multiple ways. Nevertheless, some features are repeated in different conceptualizations. In this paper I will sum up the analysis to the central definitions of relational competence, communication competence and interpersonal communication competence. In their conceptualizations features of goalaccomplishment, relational communication, adaptation, responsibility, sensitivity, and collaboration are typically emphasized (see Figure 1. Perspectives to interpersonal communication competence). Here I will first introduce the concepts, then analyze what they have in common and finally create a new definition of interpersonal communication competence from this theory-base. In this paper the terms communication and interaction are used interchangeably and understood as a process of sense-making and constructing social reality. The paper relies on the idea that interpersonal communication competence can only be achieved and occurred in social interaction. 
Figure 1. Perspectives to interpersonal communication competence

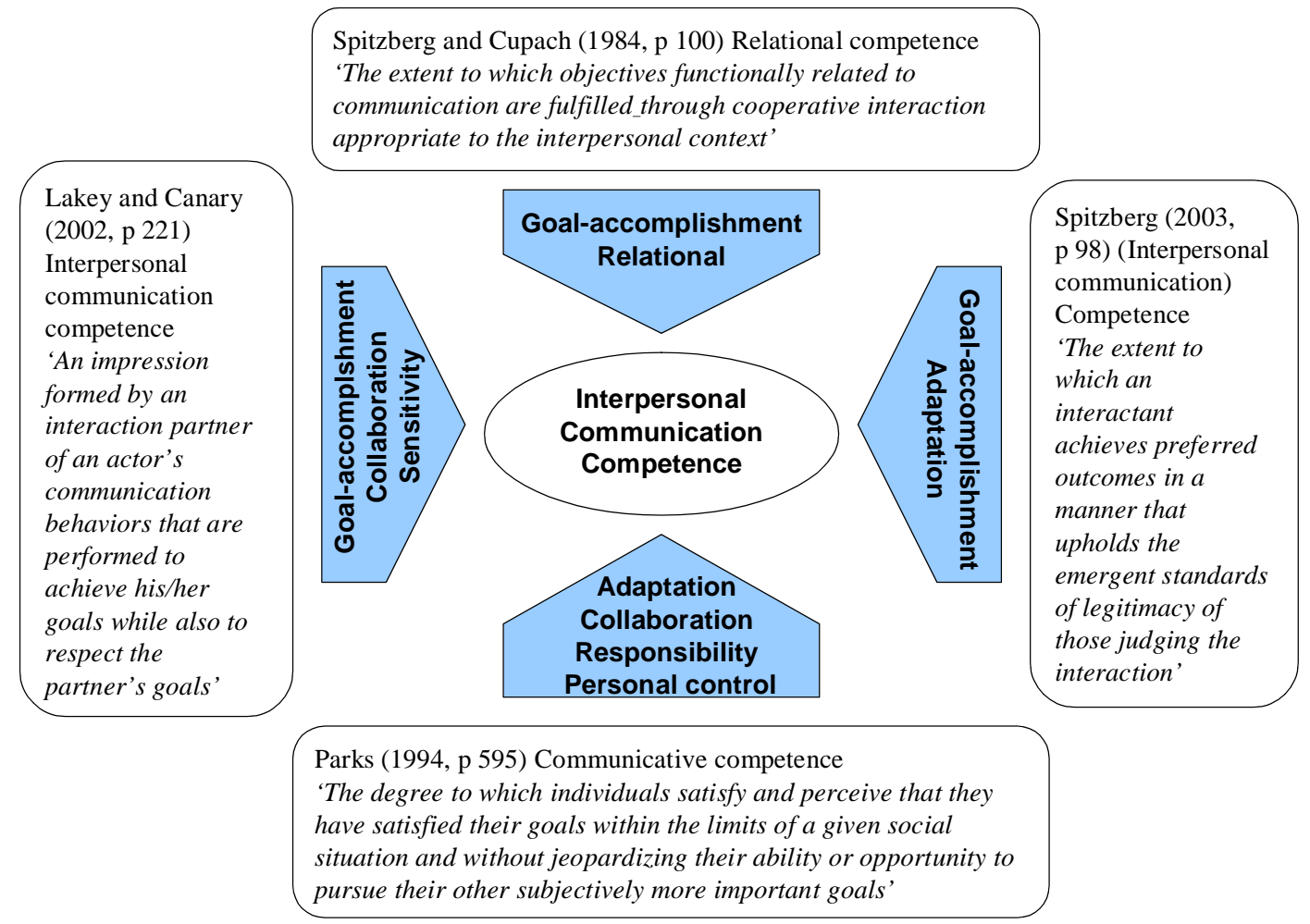

Spitzberg and Cupach (1984, p.100) conceptualize relational competence as the extent to which objectives functionally related to communication are fulfilled through cooperative interaction appropriate to the interpersonal context'. In this definition, the first of the main features related to interpersonal communication competence, accomplishing outcomes or goals in communication, is clearly included. In addition to goal-accomplishment, relational competence has been viewed as competence in creation and management of social relationships (Spitzberg \& Cupach, 1984). Parks (1994), again, associates goal-achievement in interaction with personal control. He sees goal-accomplishment as exerting control over to the environment in ways that are both adaptive and collaborative. Parks (1994) stresses, that competence implies not only goal-accomplishment but also responsibility in interaction. For him, interpersonal communication competence (communicative competence) represents

the degree to which individuals satisfy and perceive that they have satisfied their goals within the limits of a given social situation and without jeopardizing their ability or opportunity to pursue their other subjectively more important goals

(Parks 1994, p.595).

As Parks (1994) suggested, adaptation is another fundamental feature of interpersonal communication competence. As Duran and Spitzberg (1995) specify, the conceptualizations of communication competence which incorporate the concept of adaptability are concerned with the cognitive and perceptual processes of adapting one's communication behaviours across contexts. Making communication choices and enacting communication appropriate to the setting requires perceiving contextual 
parameters and identifying the variables that influence the situation. In Spitzberg's (2003, p.98) definition of (interpersonal communication) competence as 'the extent to which an interactant achieves preferred outcomes in a manner that upholds the emergent standards of legitimacy of those judging the interaction' both goalaccomplishment and adaptation are included.

Further, Lakey and Canary (2002) emphasize the sensitivity to the interaction partner and awareness of the partner's goals in interaction. They see interpersonal communication competence as 'an impression formed by an interaction partner of an actor's communication behaviours that are performed to achieve his/her goals while also to respect the partner's goals' (Lakey \& Canary 2002, p.221). An interesting question to consider is where to locate competence. Lakey and Canary explicitly illustrate interpersonal communication competence as an impression or attribution of the interaction partner. As Spitzberg (2000) clarifies, the actor and co-actor in interaction can judge the competence of themselves ('I was a competent communicator'), each other ('the other person was a competent communicator') or the interaction ('our interaction was competent') (Spitzberg 2000, p.113). Lakey and Canary's (2002) definition emphasizes also the collaborative nature of interpersonal communication competence as they argue that attention to their partners in interaction helps actors achieve their own goals. Possessing knowledge of the partner's goals can help the interactant to plan behaviours that contribute to perception of competence and on the other hand recognize the existence of incompatible goals. Further, Parks (1994) sees that many of the goals in interaction are social by nature and cannot be achieved without the aid of others.

As indicated above in different definitions, interpersonal communication competence can be outlined as a perception or evaluation and is, hence, subjective by its nature. It must be noted, that interpersonal communication competence cannot be identified as certain skills, abilities, techniques or tactics but as the evaluations attributed to these behaviours. As Spitzberg (2006) stresses, rather than in an ability or set of skills or behaviours per se, competence inheres in the social evaluation of the behaviour.

Another fundamental assumption related to interpersonal communication competence is that it is contextual by its nature. It can be argued, that same behaviour can produce different outcomes in different contexts (see Spitzberg, 2006). As Spitzberg (2003) sees it, context is a multifaceted concept, which represents at least five clusters of meaning: culture, time, relationship, place or situation and function. Behaviour evaluated as competent in one culture, relationship or situation, may not be evaluated similarly in another. Accordingly, competence in one function or one time does not imply competence in some other function or other time. All in all, context is not something 'out there' but constructed in the mind of the interactant and thereby incorporated into both action and judgments of action. Perceptions of context establish different kinds of expectations for interpersonal communication competence (Spitzberg, 2000).

In communication literature, effectiveness and appropriateness are identified as the dual criteria for interpersonal communication competence within different contexts. These criteria give a lens for evaluating interpersonal communication competence. Effectiveness in interpersonal communication has been defined as 'the extent to which a communicator achieves objectives' (Spitzberg, 2000, p.105) or as 'the 
perception that preferable relative outcomes are achieved' (Spitzberg, 2006, p.6). For example, in some contexts - e.g. conflicts - it is most competent to strive for least negative outcomes, which may not be goals of the interactant but can be preferable relative outcomes in the particular context. Depending on a context, effectiveness can subsume understanding, clarity and efficiency. When considering what is perceived as competence in social interaction, it must be noted that the features and emphasis of criteria are derived from the context of interaction. In high-context cultures, for instance, accuracy may not help accomplishing interpersonal goals like harmony in interaction.

Appropriateness, again, can be understood as the perception of suitable behaviour or behavioural legitimacy in interaction. Suitable behaviour refers to avoiding violation of valued rules, expectancies and norms. Nevertheless, sometimes to be appropriate in interpersonal communication, renegotiating the rules or norms is required. Therefore Spitzberg (2000, p.105) suggests, that appropriateness should be conceived as 'the perceived fitness or legitimacy of a communicator's behaviour in a given context rather than conformity to the previous intact rule structure of the context'. It can also be argued, that appropriateness is highly sensitive in cultural, relational and situational means (Spitzberg, 2000). In sum, effectiveness and appropriateness can be seen as complementary systems to each other. As Spitzberg (2000, p.109) states: 'communication that is both effective and appropriate is likely to be higher quality than communication that is one but not the other' (For criteria of competence see Spitzberg, 1994, 2000, 2006; Cupach \& Canary, 1997).

Most communication scholars construct interpersonal communication competence of cognitive, affective and behavioural dimensions. The cognitive dimension refers to knowledge and metacognitive skills. Interpersonal communication competence requires knowledge of communication processes, strategies and context, and metacognitive skills to perceive and analyze communication. Affective dimension can be understood as motivation for interaction and behavioural dimension as interpersonal communication skills. (For dimensions of competence, see Valkonen, 2003; Spitzberg 2003, 2006.) In Conversational Skills Rating Scale (CSRS), a widely used measure of interpersonal communication skills, these skills are classified in terms of attentiveness, composure, expressiveness and coordination. Attentiveness refers to the tendency to be interested in and attentive to a conversational partner. Composure can be understood as assertiveness and confidence, or avoidance of anxiety cues in interaction. Expressiveness relates to verbosity or nonverbal animation and finally, coordination refers to interaction management, i.e. turn-taking in conversation (see Spitzberg, 2006).

It is important to note that these three dimensions are interrelated and all included in interpersonal communication competence, in equal strength. Cognitive and affective dimension are needed to produce and display the behavioural dimension, interpersonal communication skills. Skills can be seen as the actual manifested behaviours which attempt to accomplishing goals and understanding in interaction (Spitzberg, 2003). Skills are the only one of these dimensions that is directly observable to conversational partners and third-parties of interaction. This may be a reason why skills are sometimes considered as competence. It is important to understand that skills are only one side of interpersonal communication competence. 
In addition to cognitive, affective and behavioural dimensions, a fourth dimension of interpersonal communication competence has been introduced. Valkonen (2003) suggests that to be competent in interpersonal communication, individuals must also be capable of making conscious decisions of what is legitimate or moral activity in interaction. Scholars of communication competence usually include ethics to the dual criteria of competence. As Spitzberg (2000) states, interaction that is appropriate and effective is also ethical since it adjusts the interests of others and standards of legitimacy in goal-accomplishment. In this paper the ethical principles in communicating are emphasized since the context of SME internationalization can be seen sensitive in ethical and moral ways. Ethics can incorporate different meanings among cultures, which are important to acknowledge in intercultural communication. Further, as also organizational goals are present in communication within SME internationalization, contradiction between interactants as well as values of interactants and efforts of internationalization may occur.

In this paper, interpersonal communication competence is seen as knowledge, skills, motivation and ethical principles which are perceived as effectiveness and appropriateness and fulfilled through collaborative interaction in interpersonal context. This definition emphasizes the collaborative and social nature of interpersonal communication competence. According to Lewis' (2006) analysis, in communication research collaborative interaction has been understood e.g. in terms of shared goals and shared or joint activity. This perspective is seen here preferable for interpersonal communication competence in the context of SME internationalization, since internationalization requires good social relations, collaboration as well as regional and international networking. Discussion of networking will follow in the end of this paper, but to go further with considering interpersonal communication competence in the context of SME internationalization, I will next view the concept of intercultural communication competence.

\section{Intercultural communication competence}

In literature of intercultural communication the concepts of intercultural competence and intercultural communication competence have been used rather synonymously. In general, the concept of intercultural competence roots more from sociology and psychology whereas the concept of intercultural communication competence has its roots in communication studies. Hajek and Giles (2003) argue that the empirical research in intercultural communication competence has been clustered either into work on intercultural performance or intercultural adjustment. In this paper, the interest is in interpersonal communication competence needed in SME internationalization. The definitions of intercultural competence relating on theory of long-term adjustment in a new living environment are not therefore given here attention.

Similarly to the conceptualization of interpersonal communication competence, features of relational communication, adaptation, collaboration, sensitivity and goalaccomplishment are involved in conceptualization of intercultural communication competence (see Figure 2. Perspectives to intercultural communication competence). Chen and Starosta (1996, pp.358-359) define intercultural communication competence as 'the ability to negotiate cultural meanings and to execute appropriately effective communication behaviours that recognize the interactants' multiple 
identities in a specific environment'. The study on intercultural communication competence has been criticized for following the outcome-focused approach and concentrating on competence as effective cross-cultural adaptation (see Imahori \& Lanigan, 1989). It can be argued, that Chen and Starosta's definition of intercultural communication competence combines appropriately the intercultural and interpersonal perspectives to communication competence without moving away from the interaction process. Compared to interpersonal communication competence, intercultural communication competence emphasizes more the cultural factors and cultural identity of the interactants. Flexibility may not be needed only in behaviour but also with interactant's cultural identity.

\section{Figure 2. Perspectives to intercultural communication competence}

\begin{tabular}{|c|c|c|}
\hline $\begin{array}{l}\text { Chen and Starosta } \\
\text { (1996, pp 358-359) } \\
\text { Intercultural } \\
\text { communication } \\
\text { competence } \\
\text { 'the ability to } \\
\text { negotiate cultural } \\
\text { meanings and to } \\
\text { execute appropriately } \\
\text { effective } \\
\text { communication } \\
\text { behaviors that } \\
\text { recognize the } \\
\text { interactants' multiple } \\
\text { identities in a specific } \\
\text { environment' }\end{array}$ & $\begin{array}{l}\text { Relational } \\
\text { communication } \\
\text { Adaptation } \\
\text { Collaboration } \\
\text { Sensitivity } \\
\text { Goal- } \\
\text { accomplishment }\end{array}$ & $\begin{array}{l}\text { Imahori and Lanigan } \\
\text { (1989, pp 276-277) } \\
\text { Intercultural } \\
\text { communication } \\
\text { competence } \\
\text { 'appropriate level of } \\
\text { motivation, knowledge } \\
\text { and skills of both the } \\
\text { sojourner and host- } \\
\text { national in regards to } \\
\text { their relationship, } \\
\text { leading to an effective } \\
\text { relational outcome' }\end{array}$ \\
\hline
\end{tabular}

Further, Hajek and Giles (2003) state that emphasis on relational context, together with themes of adaptation and collaboration, are the key to examination of intercultural communication competence. Imahori and Lanigan (1989, pp.276-277) define intercultural communication competence as 'appropriate level of motivation, knowledge and skills of both the sojourner and host-national in regards to their relationship, leading to an effective relational outcome'. In their definition the theorybase of relational competence is applied in intercultural context. The definition emphasizes the relational nature of intercultural communication competence, and both the outcomes and the process of communication.

Interpersonal communication competence and intercultural communication competence have also the criteria of effectiveness and appropriateness in common. An interesting point is that, according to the meta-analysis of intercultural communication competence research by Bradford, Allen \& Beissen (2000), intercultural communication competence and intercultural communication effectiveness have been operationalized as the same phenomena. Effectiveness seems to be emphasized especially in the context of professional intercultural communication. One example of this is 'a profile of the interculturally effective person', IEP, developed by an international group of researchers for the Canadian Foreign Service Institute (2000). 
In IEP profile intercultural effectiveness is seen as attitudes like modesty and respect, understanding of the concept of culture, knowledge of both host culture and self, personal and professional commitment, and skills in intercultural communication, relationship building, adaptation and organizational behaviour. Another example is the concept of overseas effectiveness, defined by Kealey (1990), which consists of professional expertise, adaptation to the environment and interest in and capacity for intercultural interaction. The relational and collaborative nature of intercultural communication competence should be acknowledged more explicitly also within the professional contexts. As it is noticed, effectiveness and appropriateness are complementary systems to each other, and efforts in sensitivity or legitimacy in communication are likely to have a positive influence on acquiring goals and outcomes in interaction.

Similarly, again, to the conceptualization of interpersonal communication competence, intercultural communication competence is constructed of affective, cognitive and behavioural dimensions. Affective dimension of intercultural communication competence can be seen as motivational and attitudinal predisposition and readiness to accommodate to intercultural challenges (Kim, 1991) or as intercultural sensitivity (Chen and Starosta, 1996, 2005). Intercultural sensitivity has been understood as acknowledgement of and respect to cultural differences (Chen \& Starosta, 1996) or as Bennett (1993, p.24) puts it, as 'the construction of reality as increasingly capable of accommodating cultural differences'. (For intercultural sensitivity see e.g. Bennett 1988, 1993.) Cognitive dimension of intercultural communication competence refers to intercultural awareness which means for example understanding and awareness of how cultures vary and how one's own identity is constructed. Finally, behavioural dimension of intercultural communication competence is illustrated as intercultural adroitness, which involves message and social skills, appropriate self-disclosure, behavioural flexibility and interaction management (Chen \& Starosta, 1996). It must be noted, again, that the above mentioned dimensions are inseparable and form a holistic picture of intercultural communication competence (see Chen and Starosta 1996, Kim 1991). As Kim (1991) puts it, behavioural dimension can be understood as carrying out what a person is capable of in cognitive and affective dimensions.

Although the ethical perspective of communication competence can be found implicitly in the conceptualization of intercultural communication competence, what seems to be neglected is the explicit explication of ethics as interrelated component of interpersonal communication competence. Nevertheless, demands have been expressed to bring ethics more prominently to the fore of competence (see Salo-Lee, 2003). Salo-Lee $(2003,2006)$ approaches the ethics in intercultural communication competence with the idea of intercultural dialogue, which reflects empathy, responsibility, and openness and sensitivity to others.

It can be argued that the dialogical perspective in context of intercultural communication competence is extensive and undetermined since, according to Johannesen (2002), the term dialogue can also be understood broadly as a two-way communication transaction. In this paper, the idea and values of intercultural dialogue are included in intercultural communication competence as ethical, affective and cognitive dimensions as well as the criterion of appropriateness in communication. Intercultural communication competence is here understood as knowledge, skills, 
motivation and ethical principles which are perceived as effectiveness and appropriateness and fulfilled through collaborative interaction in intercultural context. In intercultural context, ethical principles could mean for example accepting the other and his/her culture (see Christians \& Traber, 1997.) As can be noted, the conceptualization of interpersonal communication competence is here applied for the definition of intercultural communication competence. As Spitzberg (1989, p.261) states, 'the fundamental nature of the communication process does not change given different cultural contexts; only the contextual parameters change'. Accordingly, interpersonal communication competence takes significant cognizance of contextual features and parameters in interaction and is, therefore, applicable also in intercultural contexts.

So far the concepts of interpersonal communication competence and intercultural communication competence have been discussed and synthesized. Next, I will broaden the perspective more to networking and demands of internationalization process. I will next discuss the internationalization of SMEs more extensively and bring the concept of network competence under debate.

\section{Network competence}

SME internationalization has attained a lot of interest in business studies. Several researchers and actors in the field have emphasized networking and cooperation as essential for SME internationalization (see e.g. Lindell \& Karagozoglu, 1997). Networking and cooperation are needed both globally (Lindell \& Karagozoglu, 1997) and locally (Sternberg, 2000). Regional and local linkages to intermediary organizations, research institutions as well as manufacturing and service firms can acquire access to international networks. Developing and producing innovative products also requires information and knowledge, which can be difficult to come inside SMEs, but can be reached through networks and interaction among various organizations. (Sternberg, 2000). As networks and collaboration are realized in social interaction, networking in SME internationalization is an interest area also in communication research. As Heiss \& Monge (2007, p.1) put it 'communicating is inherently relational and relating is inherently communicative, and the coevolution of organizing and networking is achieved through communicative means'. Further, they see that all kinds of intentional and unintentional actions carried out by actors in a network are potentially of communicative value to other actors in networks.

In the field of communication, Monge and Contractor $(2001,2003)$ have conducted a remarkable study on communication networks, which they define as "patterns of contact between communication partners that are created by transmitting and exchanging messages through time and space' (Monge \& Contractor 2001, p.440). Monge and Contractor $(2001,2003)$ criticize the previous study on networks of failing to specify the theoretical mechanisms that describe how people and organizations forge, maintain and dissolve networks linkages. Aiming to contribute to the study of communication networks, they have developed the Multitheoretical, Multilevel Approach (MTML). The MTML framework refers to theories which are applicable in different aspects of social processes in tie formation, maintenance and dissolution, for example theories of self-interest and collective action, cognitions and their transmission in networks, economic exchange and resource dependency, social 
support theories, proximity and homophily and finally, evolutionary aspects of network change. (Monge \& Contractor, 2003; Heiss \& Monge, 2007)

Heiss \& Monge (2007) approach 'relating as communicating', in other words, linking in networks as communicative actions. In this paper, linking in networks is understood as social interaction. Here, the theory-base of communication networks and interpersonal communication competence are applied to consider networking in SME internationalization. The term used here for a network is interpersonal network, which is seen relative to Monge and Contractor's (2001, 2003) definition of communication networks but emphasizes the sense of social interaction. Nevertheless, the concept of interpersonal network is ambiguous and several functions can be related to it. From the functional perspective to networks, task networks exist to perform a certain task. Innovation networks create, develop and distribute new knowledge, thoughts and operational models. Finally, in social networks interpersonal relationships are created, developed and maintained. All in all, it is important to understand that different kinds of functions are not separate from each other, but networks are diverse and simultaneous. (For functions of networks, see e.g. Huotari et al, 2005). Interpersonal networks in SME internationalization can be understood as interpersonal relationships which can be pathways to for example knowledge, resources and new interpersonal relations, connected with achieving business goals.

Further, it is needed to consider what kind of competence is required in establishing and developing successful and qualified interaction networks which enhance SMEs' prerequisites in internationalization. In the field of business studies, Ritter (1999) has developed a concept of network competence to identify and describe a particular skill to handle, use and exploit inter-organizational relationships. This network competence is assessed by 'a company's degree of network management qualifications and execution of network management tasks' (Ritter 1999, p.467). By network management qualifications, Ritter (1999) means personal characteristics which allow a person to develop, maintain, and use relationships. The network management qualifications he distinguishes between specialist qualifications, like technical skills, economic skills or network knowledge and social qualifications such as communication ability, conflict management skills and cooperativeness. Further, the task execution is divided in relationship-specific tasks (i.e. tasks to maintain the relationship like transfer of information between companies) and cross-relational tasks (i.e. strategic planning or networking and realization of the plans) (Ritter, 1999; Ritter, Wilkinson \& Johnston, 2002). To put it short, network competence is supposed to measure a firm's general competence to develop and manage networks and focus on the cooperative aspects or inter-organizational relationships. (For network competence and its impact, see Ritter, 1999; Ritter \& Gemunden, 2003)

Similar to interpersonal communication competence, Ritter (1999) characterizes network competence as a contextual phenomena and sees that adaptation may be needed both in relationship-specific and cross-relational tasks. As a significant distinction to interpersonal communication competence, network competence is conceptualized merely as a skill. Network knowledge and experiential knowledge are mentioned as needed for understanding the development of the network and anticipating and evaluating critical situations but otherwise the cognitive, affective and ethical dimensions seem to be ignored. In the field of business studies skills and 
experiences seem to be emphasized as the key competencies in SME internationalization. Mughan (2003), though, suggests that in SME internationalization the international orientation of the firm owner-manager holds the key position and internationalization of business operations starts from the internal culture of the SME. Anyhow, Mughan understands the international orientation as the owner-manager's willingness to embark on a strategy of internationalization and operationalizes initiatives of the international orientation as language skills development, increased contact with foreign cultures, visits overseas and visits from overseas visitors.

In general, professions in industrial field are not traditionally understood as interpersonal professions. As the internationalizing SMEs can often be characterized as family businesses with educational backgrounds in engineering and lacking of personnel resources, interaction processes and interpersonal communication have not understandably been the priority in business development. Nevertheless, in international business, the competition for products, prices and technologies has expanded to successful development and management of collaboration and networks. Knowledge, attitudes, skills and ethical principles related to interpersonal and intercultural communication should, therefore, be brought more to the fore in SME internationalization research. Further, Mughan (2003) brings an interesting viewpoint to the discussion of SME internationalization; that in addition to external operations, internationalization is a process of development and change within the enterprise and starts from the internal communication of the SME. Therefore it requires competence in all - both internal and external - relationships.

To continue with Ritter's concept of network competence, for a communication scholar Ritter's idea of the use and exploit of relationships does not sound consistent with the values or orientation of cooperation, especially as it seems to forget appropriateness in communication. Although networking has organizational goals to enhance one's own business success, the collaborative nature of relationships should be remembered and emphasized. In light of theories of mutual self-interest and collective action, for instance, collective activity and contribution on mutual or public goods produces joint value maximization and outcomes that are unattainable by individual action (see Monge \& Contractor, 2003). It can be argued that Ritter (1999) lacks deeper understanding of interpersonal communication and relationships.

The perspective of interpersonal communication competence gives versatile possibilities to analyze networking both on the level of the interaction process and the relationship initiation and management. Due to its social, collaborative and contextual nature, it is reasoned to apply the perspective of interpersonal communication competence in SME networking and internationalization. As a conclusion of this paper, synthesis of interpersonal communication competence, intercultural communication competence and theory of communication and interpersonal networks will be made to conceptualize interpersonal communication competence in SME internationalization.

\section{Conclusions}

Relationships - both inter-firm and within a firm - are crucial elements of SME internationalization (see Ruzzier et al, 2006). It can be argued that through 
interpersonal networks SMEs get access to resources, information and further to wider national and international networks. As Lindell \& Karagozoglu (1997, p.97) put it, international competition means above all "closer relations with customers, long-term relationships with suppliers and international cooperative agreements and alliances'. It is argued in this paper that the critical competence needed for SME internationalization is interpersonal communication competence. Due to its contextual and collaborative nature, the perspective of interpersonal communication competence is applicable both in intercultural contexts as well as interpersonal networks. Networking can be seen realized in social interaction, which again, can be viewed as a collaborative process of sense-making in which contextual elements are salient (see Heiss \& Monge, 2003). As Wilson and Sabee (2003) state, a process approach (to interpersonal communication competence) which draws attention both to the interactional and psychological processes, like message production and relationship definition, can be applied in different kinds of relationships and cultural contexts.

Driven from the theory-base of interpersonal communication competence, intercultural communication competence and SME internationalization, interpersonal communication competence in SME internationalization is here understood as knowledge, skills, motivation and ethical principles which are perceived as effectiveness and appropriateness, fulfilled through collaborative interpersonal interaction in intercultural contexts and contribute to establishing, developing and maintaining interpersonal networks successful for SME internationalization. In the above definition both interpersonal and intercultural aspects are applied. Additionally, the importance of collaboration and networking both regionally and internationally to internationalize business operations is taken account.

In SME internationalization planning and implementation of organizational goals and strategies requires interpersonal communication competence. It is needed to develop understanding of the interaction process as well as understanding of collaboration as interaction. Acknowledgement of other's goals and appropriateness in interaction may have a positive influence on effective accomplishment of own goals in business meetings. Further, understanding of contextual parameters and their influence on interaction process is needed. For instance, cultural features like history, economy, or values and expectations can have their influence on message perception and interpretation.

The importance of relationships and networks is widely acknowledged in SME internationalization, but the research has mainly approached networking or relationship management as behavioural dimension, as skills. It should be remembered - as Kim (1991) puts it - that behaviours and skills are carrying out what a person is capable of in cognitive and affective dimensions. There are cogent scientific needs to bring knowledge, motivation, skills and ethical principles related to interpersonal and intercultural communication more to the fore in SME internationalization research. Further, even though discussion of international business and networking is active both in research and practice, previous research and reports (see e.g. Lindell \& Karagozoglu, 1997; Larjovuori et al, 2004) show that SMEs still lack competence needed in international trade, for example in terms of networking, knowledge of customers and cultures, gathering market information and forming international partnerships. As in rapidly globalizing world internationalization is for many SMEs rather a necessity than a choice, it can be 
argued that there are both economic and social needs for research that approaches SME internationalization as social interaction.

The present paper is based on the author's doctoral dissertation under preparation which aims to examine the perception of interpersonal communication competence in SME internationalization. Since China has become one of the central actors in international business, the research focuses on the internationalization of Finnish SMEs to China. The study aims to explore the ways in which SME owner-managers, SME employees and Finnish and Chinese intermediaries in internationalization perceive interpersonal communication competence, and scrutinize particularly the expectations and appreciations they have for interpersonal communication competence needed in networking and collaboration. From the perspective of intercultural communication, it is interesting to examine whether the perception of interpersonal communication competence will differ among Finnish and Chinese respondents. As Spitzberg (2000) states, relatively little is yet known about whether culture changes the underlying criteria by which interpersonal communication competence is judged.

Another new challenge in the $\mathrm{PhD}$ study is to apply theory of interpersonal communication competence to the study of interpersonal networks. In their paper presented at the ICA conference 2007, Heiss and Monge (2007, p.5) hope to 'engage scholars in an ongoing dialogue about the necessity, merit and possibility of designing innovative theoretical and methodological approaches informed by the infusion of network analysis with context-sensitive theorizing'. This study also aims to participate to this scientific discussion.

\section{References}

Bennett, M. J. (1988) A developmental approach to training for intercultural sensitivity. International Journal of Intercultural Relations, 10 (2): 175-195.

Bennett, M. J. (1993) Towards ethnorelativism: a developmental model of intercultural sensitivity. In: R. M. Paige, ed. Education for the intercultural experience. $2^{\text {nd }}$ ed. Yarmouth (Me.): Intercultural Press, 1993, pp 21-71.

Bradford, L., Allen, M. and Beisser, K. R. (2000) Meta-analysis of intercultural communication competence research. World Communication, 29 (1): 28-51.

Canadian Foreign Service Institute, Centre for Intercultural Learning, (2000) A profile of the interculturally effective person. Department of Foreign Affairs and International Trade, Canada.

Chen, G-M. and Starosta, W. J. (1996) Intercultural communication competence: a synthesis. In: B. R. Burleson, ed. Communication Yearbook 19. Thousand Oaks, CA: Sage Publications, Inc., 1996, pp 353-383.

Chen, G-M .and Starosta, W. J. (2005) Foundations of intercultural communication. Lanham, Maryland: University Press of America, Inc.

Christians, C. and Traber, M., eds. (1997) Communication ethics and universal values. Thousand Oaks, CA: Sage Publications, Inc. 
Duran, R. L. and Spitzberg, B. H. (1995) Toward the development and validation of a measure of cognitive communication competence. Communication Quarterly, 43 (3): 259-275.

Forsman, M., Hinttu, S. and Kock, S. (2002) Internationalization from a SME perspective. Proceedings of the 18th Annual IMP Conference, Dijon, France,September 5-7, 2002.

Hajek. C. and Giles, H. (2003) New directions in intercultural communication competence: the process model. In: J.O. Greene and B. R. Burleson, eds. Handbook of communication and social interaction skills. Mahwah: Lawrence Erlbaum Associates, Publishers, 2003, pp 935-957.

Heiss, B. M. and Monge, P. (2007) Organizational network implications of relating as communicating: Recommendations for prudent uses of the multitheoretical, multilevel framework. Paper presented at 57th Annual Conference of the International Communication Association, San Francisco, CA, May 24-28, 2007.

Huotari, M-L., Hurme, P. and Valkonen, T. (2005) Viestinnästä tietoon. Tiedon luominen työyhteisöissä [Finnish] [From communication to knowledge. Interaction and knowledge creation in organizations]. Helsinki: WSOY.

Imahori, T. T. and Lanigan, M. L. (1989) Relational model of intercultural communication competence. Intercultural Journal of Intercultural Relations, 13: 269286.

Johannesen, R. L. (2002) Ethics in Human Communication. $5^{\text {th }}$ ed. Long Growe, Illinois: Waveland Press, Inc.

Kealey, D. J. (1990) Cross-cultural effectiveness. A study of Canadian technical advisors overseas. Quebec: Canadian International Development Agency.

Kim, Y. Y. (1991) Intercultural communication competence. A systems-theoretic view. In: S. Ting-Toomey and F. Korzenny, eds. Cross-cultural interpersonal communication. Newbury Park: Sage Publication, Inc., 1991, pp 259-275.

Lakey, S. G. and Canary, D. J. (2002) Actor goal achievement and sensitivity to partner as critical factors in understanding interpersonal communication competence and conflict strategies. Communication Monographs, 69 (3): 217-235.

Larjovuori, R-L., Laiho, M. and Talonen, H. (2004) Kansainvälistyvän pk-yrityksen liiketoimintaosaamisen kehittämistarpeet [Finnish] [Development requirements for an internationalizing SME]. Ministry of Trade and Industry, Finland.

Lewis, L. K. (2006) Collaborative interaction: reviews of communication scholarship and a research agenda. In: C. S. Beck, ed. Communication Yearbook 30. Mahwah, New Jersey: Lawrence Erlbaum Associates, Publishers, 2006, pp 107-247. 
Lindell, M. and Karagozoglu, N. (1997) Global strategies of US and Scandinavian R\&D-intensive small- and medium-sized companies. European Management Journal, 15 (1): 92-100.

Monge, P. R. and Contractor, N. S. (2001) Emergence of communication networks. In: F.M. Jablin and L. L. Putnam, eds. The handbook of organizational communication. Advances in theory, research and methods. Thousand Oaks, CA: Sage Publications, Inc., 2001, pp 440-502.

Monge, P. R. and Contractor, N. S. (2003) Theories of communication networks. New York: Oxford University Press, Inc.

Mughan, T. (2003) Strategies for internationalization within SMEs: The key role of the strategic leader and the internationalization web. In: P. Kistler and S. Konivuori, eds. From international exchanges to intercultural communication. Combining theory and practice. Jyväskylä: EMICC Network and University of Jyväskylä, 2003, pp 103120.

Parks, M. R. (1994) Communicative competence and interpersonal control. In: M. L. Knapp and G. R. Miller, eds. Handbook of interpersonal communication. 2nd ed. Thousand Oaks, California: Sage Publications, Inc., 1994, pp 589-618.

Ritter, T. (1999) The networking company. Antecedents for coping with relationships and networks effectively. Industrial Marketing Management, 28: 467-479.

Ritter, T., Wilkinson, I. F. and Johnston, W. J. (2002) Measuring network competence: some international evidence. Journal of Business \& Industrial Marketing, 17 (2/3): 119-138.

Ritter, T. and Gemunden, H. G. (2003) Network competence: Its impact on innovation success and its antecedents. Journal of Business Research, 56: 745-755.

Ruzzier, M., Hisrich, R. D. and Antoncic, B. (2006) SME internationalization research: past, present and future. Journal of Small Business and Enterprise Development, 13 (4): 476-497.

Salo-Lee, L. (2003) Intercultural communication as intercultural dialogue: revisiting intercultural competence. In: Kistler, P. and Konivuori, S., eds. From international exchanges to intercultural communication. Combining theory and practice. Jyväskylä: EMICC Network and University of Jyväskylä, 2003, pp 121-128.

Salo-Lee, L. (2006) Intercultural competence research: focuses and challenges. In: Dahl, O., Jensen.I and Nynäs, P., eds. Bridges of understanding. Perspectives on intercultural communication. Oslo: Unipub forlag/ Oslo Academic Press, 2006, pp 129-140.

Spitzberg, B. H. (1989) Issues in development of a theory of interpersonal competence in the intercultural context. International Journal of Intercultural Relations, 13: 241-268. 
Spitzberg, B. H. (2000) What is good communication? Journal of the Association for Communication Administration, 29: 103-119.

Spitzberg, B. H. (2003) Methods of interpersonal skill assessment. In: J. O. Greene and B. R. Burleson, eds. Handbook of communication and social interaction skills. Mahwah, New Jersey: Lawrence Erlbaum Associates, Inc., 2003, pp 93-134.

Spitzberg, B. H. (2006) CSRS The conversational skills rating scale. An instructional assessment of interpersonal competence. NCA Diagnostic Series. Paper presented at $92^{\text {nd }}$ National Communication Association Annual Convention, San Antonio, Texas, November 16-19, 2006.

Spitzberg, B.H. and Cupach, W. R. (1984) Interpersonal communication competence. Beverly Hills, CA: Sage Publications, Inc.

Stenberg, R. (2000) Innovation Networks and Regional Development - Evidence from the European Regional Innovation Survey (ERIS): Theoretical Concepts: Methodological Approach, Empirical Basis and Introduction to the Theme Issue. European Planning Studies, 8 (4): 389-407.

Valkonen, T. (2003) Puheviestintätaitojen arviointi. Näkökulmia lukiolaisten esiintymis- ja ryhmätaitoihin [Finnish] [Assessing speech communication skills. Perspectives on presentation and group communication skills among upper secondary school students]. Jyväskylä studies in humanities 7. University of Jyväskylä.

Wilson, S. R. and Sabee, C. M. (2003) Explicating communicative competence as a theoretical term. In: J. O. Greene and B. R. Burleson, eds. Handbook of communication and social interaction skills. Mahwah, New Jersey: Lawrence Erlbaum Associates, Inc., 2003, pp 3-50. 